\title{
Moderate positive predictive value of a multiplex real-time PCR on whole blood for pathogen detection in critically ill patients with sepsis
}

\author{
Kirsten van de Groep ${ }^{1,2}$ • Martine P. Bos ${ }^{3}$ • Meri R. J. Varkila ${ }^{1,2}$ • Paul H. M. Savelkoul ${ }^{3,4,5}$ • David S. Y. Ong ${ }^{1,6}$. \\ Lennie P. G. Derde ${ }^{2} \cdot$ Nicole P. Juffermans $^{7} \cdot$ Tom van der Poll $^{8,9} \cdot$ Marc J. M. Bonten $^{1,10} \cdot$ Olaf L. Cremer $^{2} \cdot$ on behalf of $^{-}$ \\ the MARS consortium
}

Received: 22 April 2019 / Accepted: 12 June 2019 / Published online: 26 June 2019

(C) The Author(s) 2019

\begin{abstract}
A novel multiplex real-time PCR for bloodstream infections (BSI-PCR) detects pathogens directly in blood. This study aimed at determining the positive predictive value (PPV) of BSI-PCR in critically ill patients with sepsis. We included consecutive patients with presumed sepsis upon admission to the intensive care unit (ICU). The multiplexed BSI-PCR included 17 individual PCRs for a broad panel of species- and genus-specific DNA targets. BSI-PCR results were compared with a reference diagnosis for which plausibility of infection and causative pathogen(s) had been prospectively assessed by trained observers, based on available clinical and microbiological evidence. PPV and false positive proportion (FPP) were calculated. Clinical plausibility of discordant positive results was adjudicated by an expert panel. Among 325 patients, infection likelihood was categorized as confirmed, uncertain, and ruled out in 210 (65\%), 88 (27\%), and $27(8 \%)$ subjects, respectively. BSI-PCR identified one or more microorganisms in $169(52 \%)$ patients, of whom $104(61 \%)$ had at least one detection in accordance with the reference diagnosis. Discordant positive PCR results were observed in 95 patients, including 30 subjects categorized as having an "unknown" pathogen. Based on 5525 individual PCRs yielding 295 positive results, PPV was 167/295 (57\%) and FPP was 128/5525 (2\%). Expert adjudication of the 128 discordant PCR findings resulted in an adjusted PPV of $68 \%$ and FPP of $2 \%$. BSI-PCR was all-negative in 156 patients, including 79 (51\%) patients in whom infection was considered ruled out. BSI-PCR may complement conventional cultures and expedite the microbiological diagnosis of sepsis in ICU patients, but improvements in positive predictive value of the test are warranted before its implementation in clinical practice can be considered.
\end{abstract}

Keywords Diagnostic research $\cdot$ Pathogen detection $\cdot$ Sepsis $\cdot$ Intensive care $\cdot$ Multiplex real-time PCR

Electronic supplementary material The online version of this article (https://doi.org/10.1007/s10096-019-03616-w) contains supplementary material, which is available to authorized users.

Kirsten van de Groep

k.vandegroep-3@umcutrecht.nl

1 Julius Center for Health Sciences and Primary Care, University Medical Center Utrecht, Utrecht University,

Utrecht, The Netherlands

2 Department of Intensive Care Medicine, University Medical Center Utrecht, Utrecht University, Utrecht, The Netherlands

3 Microbiome, Amsterdam, The Netherlands

4 Department of Medical Microbiology \& Infection Control, Amsterdam University Medical Centers, VU, Amsterdam, The Netherlands
5 Department of Medical Microbiology, Maastricht University Medical Center, Maastricht, The Netherlands

6 Department of Medical Microbiology and Infection Control, Franciscus Gasthuis \& Vlietland, Rotterdam, The Netherlands

7 Department of Intensive Care, Amsterdam University Medical Centers, Academic Medical Center, University of Amsterdam, Amsterdam, The Netherlands

8 Center of Experimental and Molecular Medicine, Amsterdam University Medical Centers, Academic Medical Center, University of Amsterdam, Amsterdam, The Netherlands

9 Division of Infectious Diseases, Amsterdam University Medical Centers, Academic Medical Center, University of Amsterdam, Amsterdam, The Netherlands 


\section{Introduction}

Diagnosing sepsis can be challenging in critically ill patients having multiple concurrent disease processes. Collection of microbiological evidence for infection is therefore of importance to establish the diagnosis and optimize antimicrobial treatment [1]. However, sensitivity of culture-based methods is suboptimal and previous antibiotic exposure may render results unreliable [2-4]. Moreover, turnaround times for culture-based methods (if used in combination with MALDI-TOF MS identification) range from 12 to $72 \mathrm{~h}$ from sampling until final result [5]. As a result, initiation of antimicrobial treatment in the intensive care unit (ICU) is mostly empirical [6].

Several molecular approaches have been developed in an attempt to improve the diagnosis of sepsis - and bloodstream infections (BSI) in particular - in critically ill patients $[2,7]$. We previously described the development of a novel multiplex real-time PCR assay to detect microbial DNA directly in whole blood (which will further be referred to as BSI-PCR) [8]. This test combines 17 individual PCRs, creating a broad panel of species- and genus-specific DNA targets as well as some generic ones [8]. We previously compared BSI-PCR with standard blood culture (BC) in 347 samples and found that sensitivity was acceptable for most bacterial speciesspecific PCRs (varying from 65 to $100 \%$ ), yet still remained insufficient for yeasts and some generic targets [8]. However, that study could not assess the clinical significance of positive BSI-PCR findings, due to a design that focused on blood samples that were merely selected based on the result of a paired BC, which itself has imperfect sensitivity.

In contrast, the current study was performed in a clinically relevant population of patients with suspected sepsis at ICU admission. Moreover, we did not solely compare the new test to $\mathrm{BC}$ results but used a prospectively recorded clinical reference diagnosis which considered all cultured pathogens that could potentially be relevant in relation to the presumed site of infection. However, this implies that, for negative BSI-PCR results, no certain distinction could be made between false negative findings (i.e., the test potentially failed to detect a clinically relevant pathogen) and true negative findings (i.e., the non-detected microorganism was merely a colonizer or contaminant). Therefore, our study aimed at estimating the positive predictive value (PPV) and the false positive proportion (FPP) of BSI-PCR in a clinically relevant context, without specifically evaluating other measures of diagnostic accuracy.

\section{Materials and methods}

\section{Study population}

Patients were prospectively enrolled as part of the Molecular Diagnosis and Risk Stratification of Sepsis (MARS) cohort in two tertiary ICUs in the Netherlands between January 2012 and June 2014. Ethical approval for the study was provided by the Medical Ethics Committee of the University Medical Center Utrecht, including an opt-out consent method (IRB No. 10-056C). We selected consecutive patients with presumed sepsis, who had been admitted to ICU within $48 \mathrm{~h}$ of infection onset (i.e., start of antimicrobial treatment) and in whom blood cultures were obtained at the discretion of the attending physician. Enrolment took place before the introduction of the sepsis-3 criteria [9]; thus, patients were included based on the sepsis-2 "severe sepsis" and "septic shock" definitions [10]. However, only six (2\%) subjects did not fulfil current sepsis- 3 criteria in retrospect. Patients already receiving treatment for another infection for more than 2 days were excluded.

\section{Sample collection and BSI-PCR assay}

BSI-PCR samples were collected at the same time that BCs were performed during ICU admission. For each set of BCs (i.e., a single set of aerobic and anaerobic vials), a $5 \mathrm{~mL}$ blood tube was drawn from the same catheter hub or venepuncture site. For patients having multiple or subsequent samples, we analyzed only the first available one. Blood samples were stored at $4{ }^{\circ} \mathrm{C}$ for a maximum of 3 days before processing. BSI-PCR was performed in $5 \mathrm{~mL}$ whole blood, as described in detail previously, resulting in DNA isolate volumes representative of $0.71 \mathrm{~mL}$ blood per individual PCR [8]. Technicians performing tests and interpreting PCR results were blinded for clinical and microbiological findings. Of note, the multiplex BSI-PCR panel consisted of 17 individual PCRs; thus, each sample could yield multiple positive results.

\section{Reference diagnosis}

For each suspected sepsis episode, both the post hoc plausibility of true infection and the most likely causative pathogen(s) were prospectively adjudicated by trained physicians, who attended daily multidisciplinary clinical meetings and had full access to all clinical data as part of the MARS study [11]. For use as reference diagnosis, infection was considered confirmed only if the plausibility of infection had been rated either probable or definite according to criteria described previously [11]. Reference pathogen(s) were those that had been assigned as likely causative microorganism(s) during prospective adjudication considering all microbiological evidence available (i.e., acquired either before, during, or after ICU admission). However, it should be noted that the reference pathogen was classified as "unknown" if no pathogens had been identified (ever), and if all cultured microorganisms were considered to be not potentially relevant in relation to the presumed site of infection. All observers contributing to the reference diagnosis were blinded for BSI-PCR results. 
Of importance, no distinction could be made between false negative and true negative BSI-PCR findings, because the reference pathogens incorporated all identified pathogens in relation to the presumed site of infection without a certain distinction between true causative pathogens and colonization. BSI-PCR should thus not be expected to identify all potential pathogens considered by the reference diagnosis. Consequently, not all microorganisms "missed" by BSI-PCR were classified as a false negative result. For example, for a patient with hospital-acquired pneumonia in whom sputum cultures yielded growth of both Staphylococcus aureus and Pseudomonas aeruginosa, both species were registered as a potential reference pathogen. However, we did not consider BSI-PCR to return a false negative result if the test identified only one of these two bacteria. For this reason, our study focused on the interpretation of positive BSI-PCR results and does not include evaluation of pathogens potentially "missed" by BSI-PCR.

\section{Evaluation of BSI-PCR}

In our primary analysis, we compared BSI-PCR results to the reference pathogen(s) and classified all discordant PCR findings as false positive. Since BSI-PCR yields 17 results per patient, the test could simultaneously have both true and false positive findings. Such instances were classified as "partial true positive." In a secondary analysis, we compared BSIPCR results with the results of BC. Furthermore, we assessed whether cycle times $(\mathrm{Ct})$-values differed between true and false positive PCR results.

In a pre-planned discrepancy analysis, we reassessed all positive BSI-PCR results that were discordant to the reference (including "unknown" reference pathogens) in order to adjust for potentially suboptimal sensitivity of the culture-based techniques used in establishing the reference diagnosis. Case vignettes (see Appendix I) were created and evaluated by an expert panel consisting of intensivists (LD or OC) and clinical microbiologists (DO or MB). All detections by BSI-PCR that were not included as reference pathogens were subsequently re-classified as true positive, false positive, or undetermined. Of note, panelists had agreed that bacterial translocation was to be considered a plausible cause of DNAemia by Enterobacteriaceae, Enterococci, and Candida in sepsis patients having intestinal ischemia, bowel perforation, or overt abdominal compartment syndrome, and in the presence of advanced liver failure [12, 13].

In a final explorative analysis, we assessed the possible impact of BSI-PCR on the choice of antimicrobial therapy as given on the first day in ICU. As the sensitivity of BSIPCR is currently considered insufficient to rule out bacteremia in critically ill patients with confidence [8], we did not evaluate whether de-escalation was indicated based on BSI-PCR results. A clinical microbiologist (DO or $\mathrm{MB}$ ) thus evaluated only whether positive PCR results would have led to a broader choice in antimicrobial coverage.

\section{Statistical analysis}

For the primary analysis, we calculated PPV and FPP with exact confidence intervals (CI). FPP was calculated by dividing the number of false positive results by the total number of individual PCR's performed. Since no certain distinction could be made between true negative and false negative BSI-PCR results (as explained above), it was unfeasible to calculate estimates for sensitivity, specificity, and negative predictive values. For the discrepancy analysis, we adjusted these parameters based on the expert panel adjudication. Since this reclassification introduced an "undetermined" category, a range of estimates was calculated (i.e., first classifying the undetermined cases as false positives, and subsequently as true positives). Differences between groups were assessed using chi-square, Wilcoxon rank sum, or Fisher's exact tests, as appropriate. All analyses were performed using SAS Enterprise Guide 7.1 (SAS Institute, Cary, NC), and figures were made using GraphPad Prism version 7.04 (GraphPad Software, La Jolla, CA, USA).

\section{Results}

\section{Patient and infection characteristics}

Among 791 eligible patients admitted to ICU with presumed sepsis, 325 (41\%) were included in the current study (Fig. 1). Study exclusions were mostly due to omissions of BC and/or paired BSI-PCR blood sampling at the time of ICU admission. Of note, many patients (also) had cultures taken prior to ICU presentation and all subjects were clinically suspected of (and treated for) sepsis. However, based on post hoc adjudication, infection likelihood was categorized as confirmed, uncertain, and ruled out in 210 (65\%), 88 (27\%), and 27 (8\%) patients, respectively (Table 1). Among study patients, median APACHE-IV scores were 85 (interquartile range (IQR) 68109) and half of patients presented with septic shock. Sepsis had community-acquired onset in 188 (58\%) patients, and the most common infection sites included the respiratory tract and abdomen.

\section{BSI-PCR findings}

BSI-PCR yielded one or more pathogen detections in 169 (52\%) patients, with a median of 2 (IQR 1-2) positive PCRs per patient. According to the primary analysis, these results were considered true positive in $74(44 \%)$, partial true positive in $30(18 \%)$, and false positive in $65(38 \%)$ patients (Fig. 2). 
Fig. 1 Patient inclusion. $B S I$ bloodstream infection; $I C U$ intensive care unit; $P C R$ polymerase chain reaction

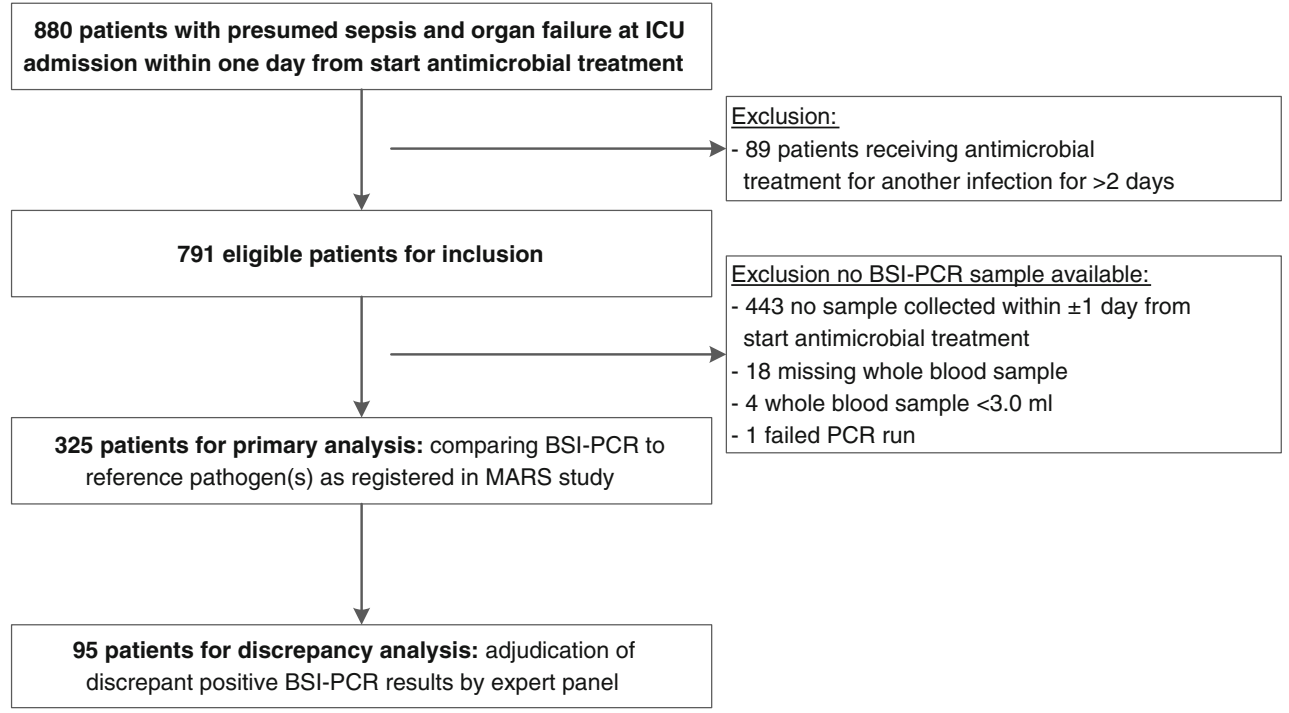

Among these latter 65 subjects, infection was considered ruled out in four and the causative pathogen was unknown in 30 according to the reference diagnosis. By comparison, 47 pathogens had been identified by BC in $43(13 \%)$ patients and seven of these isolates had been considered contaminants during the prospective adjudication process. BSI-PCR identified $25(63 \%)$ of the remaining $40 \mathrm{BC}$ isolates.

In the discrepancy analysis, the expert panel adjudicated 128 apparently false positive PCR results in 95 patients (i.e., 35 detections in 30 patients classified as partial true positive, and 93 detections in 65 patients classified as false positive). Thirty-four (27\%) of these PCR results were unanimously reclassified as true positive, whereas $10(8 \%)$ and $84(66 \%)$ discordant results remained unresolved and false positive, respectively. Among the 169 patients having (one or more) positive BSI-PCR results, panel review thus resulted in adjusted true positive, partial true positive, and false positive rates of $100(59 \%), 6(4 \%)$, and 63 (37\%), respectively.

\section{Assessment of individual PCR performance}

Among 325 patients, multiplex BSI-PCR generated a total of 5525 single PCR results, of which 295 were positive. This resulted in a PPV of 167/295 (57\%, 95\% CI 51-62\%) overall, with estimates for individual species-specific and generic PCRs ranging $16-82 \%$ and $46-91 \%$, respectively (Table 2). Overall FPP was $2 \%$ (95\% CI 2-3\%) based on the 128 discordant positive results observed according to the primary analysis (individual estimates ranging $0-8 \%$ and $0-4 \%$, respectively). Ctvalues were significantly lower for the 167 true positive detections than for the 128 false positive results (median 31.9 (IQR 27.8-35.7) versus median 37.9 (IQR 35.6-40.0); $p<0.001$ ).

Adjudication of discordant positive results by the expert panel resulted in an adjusted overall PPV ranging from 68 to $72 \%$, depending on whether results classified as undetermined were analyzed as false or true positive finding (Table 2). Overall FPP remained 2\%. We observed no positive methicillin resistance PCRs, none of the species-specific Candida PCRs were positive, and the PCRs for the extended spectrum beta-lactamase resistance gene (CTX-M1,9) were uniformly negative as well; this precluded calculation of PPV and FPP for these targets.

\section{Potential therapeutic impact of BSI-PCR findings}

Among the 169 patients with positive BSI-PCR findings, there were 55 (33\%) cases in which the identified pathogens were not covered by the antimicrobial regimen as given on the first day in ICU. Based on expert review, BSI-PCR results could have led attending physicians to consider broadening of initial antimicrobial coverage in $37(22 \%)$ of these episodes, mainly to assure additional treatment of $P$. aeruginosa $(n=25)$ and Enterococci $(n=6)$. However, as findings were considered false positive in $20(54 \%)$ of these 37 patients, the potential benefit of BSI-PCR-guided antibiotic therapy was limited to 17 (5\%) of 325 patients at most.

\section{Patients with negative BSI-PCR results}

Among 156 (48\%) patients with negative BSI-PCR, infection was classified as ruled out according to the reference diagnosis in $23(15 \%)$ cases. Six $(4 \%)$ other patients had only viral pathogens and could therefore also be considered to have a true negative BSI-PCR result. Among the 127 remaining patients, infection was considered uncertain and confirmed in 54 (35\%) and $73(57 \%)$ cases, respectively. Particularly in the latter group, BSI-PCR probably represented a false negative result. Among these were five patients in whom $\mathrm{BC}$ grew Enterobacteriaceae, Bacteroides species, or Gram-positive pathogens. 
Table 1 Characteristics of 325 patients with presumed sepsis at ICU admission

\begin{tabular}{|c|c|}
\hline Variables & $\begin{array}{l}\text { Study population } \\
(n=325)\end{array}$ \\
\hline \multicolumn{2}{|l|}{ Patient characteristics } \\
\hline Sex (male) & $186(57 \%)$ \\
\hline Age (years) & $63(52-72)$ \\
\hline Chronic obstructive pulmonary disease & $45(14 \%)$ \\
\hline Diabetes mellitus & $65(20 \%)$ \\
\hline Solid or hematologic malignancy & $84(26 \%)$ \\
\hline Chronic renal insufficiency & $46(14 \%)$ \\
\hline Charlson comorbidity index & $1(0-2)$ \\
\hline Immune deficiency & $57(18 \%)$ \\
\hline \multicolumn{2}{|l|}{ Admission characteristics } \\
\hline Recent surgery & $62(19 \%)$ \\
\hline Prior ICU admission & $55(17 \%)$ \\
\hline APACHE-IV score & $85(68-109)$ \\
\hline C-reactive protein $(\mathrm{mg} / \mathrm{L})^{\mathrm{a}}$ & $212(95-305)$ \\
\hline White blood cell count $\left(10^{9} / \mathrm{L}\right)^{\mathrm{a}}$ & $16(10-21)$ \\
\hline Septic shock & $164(50 \%)$ \\
\hline SOFA-score on day 1 & $9(7-11)$ \\
\hline Length of stay in ICU & $5(3-13)$ \\
\hline Mortality after 30 days & $107(33 \%)$ \\
\hline \multicolumn{2}{|l|}{ Infection characteristics } \\
\hline Community-acquired onset & $188(58 \%)$ \\
\hline \multicolumn{2}{|l|}{ Presumed source: } \\
\hline - Lower respiratory tract & $152(47 \%)$ \\
\hline - Abdomen & $79(24 \%)$ \\
\hline - Urinary tract & $24(7 \%)$ \\
\hline - Other & $61(19 \%)$ \\
\hline - Unknown & $9(3 \%)$ \\
\hline \multicolumn{2}{|l|}{ Post hoc plausibility of infection: ${ }^{\text {b }}$} \\
\hline - Definite & $127(39 \%)$ \\
\hline - Probable & $83(26 \%)$ \\
\hline - Uncertain & $88(27 \%)$ \\
\hline - Ruled out & $27(8 \%)$ \\
\hline
\end{tabular}

APACHE Acute Physiology And Chronic Health Evaluation, ICU intensive care unit, $L O S$ length of stay, SOFA Sequential Organ Failure Assessment. Data are presented as frequencies (\%) or medians (Q1-Q3)

${ }^{a}$ Missing data: C-reactive protein $n=106$ (33\%), and white blood cell count $n=3(2 \%)$

${ }^{\mathrm{b}}$ Based on post hoc assessment of plausibility of infection by trained physicians based on all clinical information as described elsewhere [11]

\section{Discussion}

In this diagnostic cohort study, we evaluated a novel multiplex PCR test on whole blood for rapid pathogen detection in ICU patients with presumed sepsis. BSI-PCR detected one or more pathogens in half of the patients. These findings were considered true positive in $44 \%$ and partial true positive in $18 \%$ of

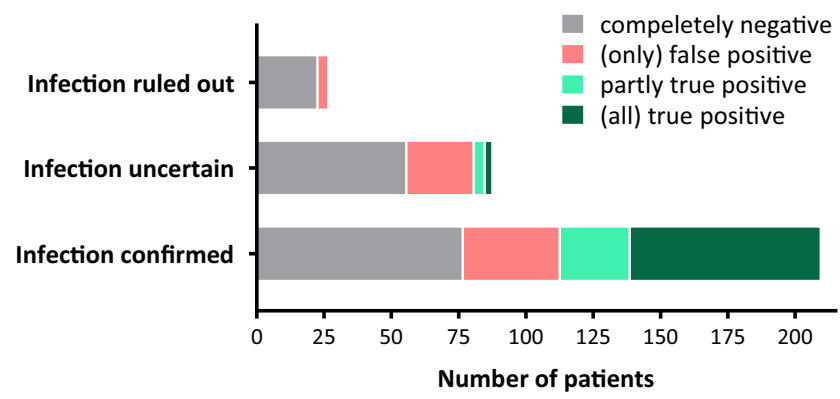

Fig. 2 BSI-PCR performance on patient level by infection plausibility of reference diagnosis. Plausibility of infection was considered confirmed in patient with a post hoc likelihood of infection rated as probable or definite. Since BSI-PCR is a multiplex real-time PCR containing $17 \mathrm{mi}-$ crobiological targets, multiple positive results were possible per patient. Therefore, patients with both true positive and false positive results were classified as "partly true positive"

the episodes, when compared with prospectively assigned reference pathogens. PPV was $68 \%$ after adjudication of discrepant pathogens detected by BSI-PCR. False positive results were observed in about a third of included patients, and BSIPCR failed to identify a reference pathogen in $54 \%$ of all patients in whom infection was considered present.

This study demonstrates that PCR-based technologies may complement $\mathrm{BC}$ in pathogen identification in sepsis patients, because of additionally identified causative pathogens and theoretically faster results. This is in line with previously performed evaluations of other molecular-based assays for pathogen identification directly on whole blood [5, 14-19]. In general, these validation studies show relatively low sensitivity and reasonable specificity for the multiplex-PCR assays but results are very heterogeneous $[2,5]$. Furthermore, direct comparison of the PPV of BSI-PCR observed in our study with other results is hampered by large differences in study populations and used reference diagnoses.

Based on the current study of BSI-PCR performance, as well as a previously published direct comparison with paired $\mathrm{BC}$ samples obtained from a different patient population [8], we hold the opinion that the diagnostic accuracy of the test is still insufficient for implementation in clinical practice at this time. The first issue relates to suboptimal sensitivity. In fact, BSI-PCR did not (correctly) identify a pathogen in 54\% of patients with a confirmed infection. Of note, this false negative rate was lower than that of the paired $\mathrm{BC}$, which did not yield growth in $82 \%$ of these cases. Furthermore, dissemination of (non-viable) pathogens to the bloodstream is required for a positive BSI-PCR but it is unclear to what extent this occurs in patients with various local sites of infection. Moreover, BSI-PCR is also not designed to fully replace culture-based methods, since the assay provides only limited information about antimicrobial susceptibility and does not cover infrequently found bacteria and fungi. A second issue relates to the frequent occurrence of false positive detections. Although the FPP of individual PCRs was mostly acceptable, 
Table 2 Evaluation of positive BSI-PCR results in 196 critically ill patients with presumed sepsis

\begin{tabular}{|c|c|c|c|c|c|c|c|c|c|}
\hline \multirow[t]{3}{*}{ Pathogen or target } & \multirow[b]{3}{*}{$(n)$} & \multicolumn{4}{|c|}{ Primary analysis ${ }^{\mathrm{a}}$} & \multicolumn{4}{|c|}{ Discrepancy analysis ${ }^{\mathrm{b}}$} \\
\hline & & \multicolumn{2}{|c|}{ True positive } & \multicolumn{2}{|c|}{ False positive } & \multicolumn{2}{|c|}{ True positive range } & \multicolumn{2}{|c|}{ False positive range } \\
\hline & & $n$ (PPV) & $(95 \% \mathrm{CI})$ & $n(\mathrm{FPP})$ & $(95 \% \mathrm{CI})$ & $n$ & (PPV) & $n$ & (FPP) \\
\hline \multicolumn{10}{|c|}{ A. Species-specific PCRs } \\
\hline E. faecalis & (16) & $7(44 \%)$ & $(20-70)$ & $9(3 \%)$ & $(1-5)$ & $11-12$ & $(69-75 \%)$ & $4-5$ & $(1-2 \%)$ \\
\hline E. faecium & (11) & $9(82 \%)$ & $(48-98)$ & $2(1 \%)$ & $(0-2)$ & 10 & $(91 \%)$ & 1 & $(0 \%)$ \\
\hline S. aureus & (34) & $15(44 \%)$ & $(27-62)$ & $19(6 \%)$ & $(4-9)$ & $15-18$ & $(44-53 \%)$ & $16-19$ & $(5-6 \%)$ \\
\hline S. pneumoniae & (17) & $12(71 \%)$ & $(44-90)$ & $5(2 \%)$ & $(1-4)$ & 13 & $(76 \%)$ & 4 & $(1 \%)$ \\
\hline A. baumannii & (1) & 0 & - & $1(0 \%)$ & $(0-2)$ & $0-1$ & $(0-100 \%)$ & $0-1$ & $(0-0 \%)$ \\
\hline E. coli & $(58)$ & $33(57 \%)$ & $(43-70)$ & $25(8 \%)$ & $(5-11)$ & $45-46$ & $(78-79 \%)$ & $12-13$ & $(4-4 \%)$ \\
\hline Klebsiella & (11) & $7(64 \%)$ & $(31-90)$ & $4(1 \%)$ & $(0-3)$ & $9-10$ & $(82-91 \%)$ & $1-2$ & $(0-1 \%)$ \\
\hline$P$. aeruginosa & $(32)$ & $5(16 \%)$ & $(5-33)$ & $27(8 \%)$ & $(6-12)$ & $5-7$ & $(16-22 \%)$ & $25-27$ & $(8-8 \%)$ \\
\hline C. albicans & $(0)$ & - & & - & & - & & - & \\
\hline C. glabrata & $(0)$ & - & & - & & - & & - & \\
\hline C. krusei & $(0)$ & - & & - & & - & & - & \\
\hline Total A. & $(180)$ & $88(49 \%)$ & $(41-56 \%)$ & $92(3 \%)$ & $(2-3 \%)$ & $108-117$ & $(60-65 \%)$ & $63-72$ & $(2-2 \%)$ \\
\hline \multicolumn{10}{|l|}{ B. Generic PCRs } \\
\hline Enterococcus & $(25)$ & $12(48 \%)$ & $(28-69)$ & $13(4 \%)$ & $(2-7)$ & $16-17$ & $(64-68 \%)$ & $8-9$ & $(2-3 \%)$ \\
\hline Staphylococcus & (24) & $11(46 \%)$ & $(26-67)$ & $13(4 \%)$ & $(2-7)$ & 12 & $(50 \%)$ & 12 & $(4 \%)$ \\
\hline Gram-positive & $(30)$ & $25(83 \%)$ & $(65-94)$ & $5(2 \%)$ & $(1-4)$ & 30 & $(100 \%)$ & 0 & - \\
\hline Gram-negative & (33) & $30(91 \%)$ & $(76-98)$ & $3(1 \%)$ & $(0-3)$ & 33 & $(100 \%)$ & 0 & - \\
\hline 3Candida & (2) & $1(50 \%)$ & $(1-99)$ & $1(0 \%)$ & $(0-2)$ & 2 & $(100 \%)$ & 0 & - \\
\hline Pan-Aspergillus & (1) & 0 & - & $1(0 \%)$ & $(0-2)$ & 0 & - & 1 & $(0 \%)$ \\
\hline Total B. & $(115)$ & $79(69 \%)$ & $(59-77)$ & $36(2 \%)$ & $(1-3)$ & 93-94 & $(81-82 \%)$ & $21-22$ & $(1-1 \%)$ \\
\hline Total & $(295)$ & $167(57 \%)$ & $(51-62)$ & $128(2 \%)$ & $(2-3)$ & $201-211$ & $(68-72 \%)$ & $84-94$ & $(2-2 \%)$ \\
\hline
\end{tabular}

$n$, number of positive BSI-PCR results (multiple positive results possible per patient); $C I$, confidence interval; $P P V$, positive predictive value (= true positive/(true positive + false positive)); FPP, false positive proportion (= false positive/total number performed $(n=325$ per PCR))

${ }^{a}$ For the primary analysis positive BSI-PCR results were compared with the reference pathogens based on a prospective registration of most likely causative pathogen(s) within the MARS study

${ }^{\mathrm{b}}$ For the discrepancy analysis, false positive BSI-PCR results based on the primary analysis were adjudicated by an expert panel. Since 10 results were classified as "undetermined" by the panelists, a range was calculated for the PPV and FPP by classifying the undetermined results firstly as false positive and subsequently as true positive

the multiplex nature of BSI-PCR yields a large number of test results, thus increasing the overall rate of false positive findings to $29 \%$. These may be due to DNA contamination during sample processing in the laboratory or by the presence of (non-viable) microbes in the circulation. In clinical practice, it would be challenging to distinguish true from false positive results but the semi-quantitative measurement of microbial DNA load (expressed as Ct-values) appeared to be discriminative and could be used as guidance. In the current study, we did not recommend specific cut-off points for $\mathrm{Ct}$ values, as optimal trade-off between sensitivity and specificity will likely vary across clinical scenarios.

An important strength of this study was the prospective registration of reference diagnosis and reference pathogens by trained observers within the parent cohort of the MARS study. Furthermore, we corrected our estimates of test accuracy for the suboptimal sensitivity of conventional cultures through re-adjudication by an expert panel. Finally, we included a large population of presumed sepsis patients with various underlying infectious diseases, which created a heterogeneous population representative for clinical practice. Nevertheless, we also consider the reference diagnosis as suboptimal, because, based on culture results, no confident distinction could be made between colonization and true causative pathogens. In addition, inter-observer agreement for the registration of causative pathogens was previously reported to be only $70 \%$ [11], and because classification was based on clinically performed microbiological testing, which may still be incomplete. Therefore, future studies should assess the diagnostic accuracy of BSI-PCR in a prospective intervention study, which should incorporate the assessment of test results on antimicrobial therapy and cost effectiveness. 
In conclusion, this clinical evaluation demonstrated that BSI-PCR had only moderate PPV. Furthermore, the test identified potential pathogen(s) in no more than half of patients having a high likelihood of infection. This precludes any consideration of clinical implementation of BSI-PCR at this time. However, the assay is still under development and its accuracy will likely be improved by the use of larger blood input volumes and implementation on a fully automated cartridgebased platform for sample processing. In the future, the potential to provide rapid results could make BSI-PCR - and similar assays - of additional value for pathogen detection in critically ill patients with presumed sepsis.

Acknowledgments We thank the MARS consortium, including participating ICUs and (research) nurses for their logistical support and help in data acquisition for this project. We thank Anna Rubenjan and Christel Gazenbeek for sample processing and performing all BSI-PCR assays.

Members of the MARS Consortium:

Amsterdam University Medical Centers, University of Amsterdam $(N L)$ : Friso M. de Beer, MD; Lieuwe D. J. Bos, MD, PhD; Gerie J. Glas, MD; Arie J. Hoogendijk, PhD; Roosmarijn T. M. van Hooijdonk, $\mathrm{MD}, \mathrm{PhD}$; Janneke Horn MD, PhD; Mischa A. Huson, MD, PhD; Nicole P. Juffermans, MD, PhD; Tom van der Poll, MD, PhD; Laura R. A. Schouten, MD; Brendon Scicluna, PhD; Marcus J. Schultz, MD, PhD; Marleen Straat, MD, PhD; Lonneke A. van Vught, MD, PhD; Luuk Wieske, MD, PhD; Maryse A. Wiewel, MD, PhD; Esther Witteveen, $\mathrm{MD}, \mathrm{PhD}$. University Medical Center Utrecht, Utrecht University (NL): Marc J.M. Bonten, MD, PhD; Olaf L. Cremer, MD, PhD; Jos F. Frencken, MD, PhD; K. van de Groep, MD; Peter M.C. Klein Klouwenberg, MD, PharmD, PhD; Maria E. Koster-Brouwer, MSc; David S.Y. Ong, MD, PharmD, PhD; Meri R.J. Varkila MD; Diana M. Verboom, MD.

Work package 'Pathogen Detection': Microbiome, Amsterdam (NL): Martine P. Bos, PhD; Paul H.M. Savelkoul, PhD; Arnold Catsburg. Biocartis, Mechelen (BE): Bart van Meerbergen, PhD; Sarah Berghmans, BSc. Radboud University Nijmegen (NL): Dimitri Diavatopoulos, PhD; Marrit Habets, MSc; Eveline Snelders, PhD; Jan Zoll, PhD. Checkpoints, Wageningen (NL): Pieter Vos, PhD; Aneta Karczmarek, PhD; Philips, Eindhoven (NL): Sigi Neerken, PhD; Paul van de Wiel, $\mathrm{PhD}$.

Funding This work was supported by the Center for Translation Molecular Medicine (http://www.ctmm.nl), project MARS (grant 041201) and subsequent project MARS\&MORE (grant 09P-107). The sponsor did not play a role in the design and conduct of the study; collection, management, analysis, and interpretation of the data; and preparation, review, or approval of the manuscript; and decision to submit the manuscript for publication.

\section{Compliance with ethical standards}

Conflict of interest Authors KvdG, MRJV, DSYO, LPGD, NPJ, TvdP, MJMB, OLC declare that they have no conflicts of interest related to the subject matter. Author MPB is an employee of Microbiome and PHMS is a shareholder of Microbiome.

Ethical approval All procedures performed in studies involving human participants were in accordance with the ethical standards of the institutional and/or national research committee and with the 1964 Helsinki declaration and its later amendments or comparable ethical standards. For this study an opt-out informed consent method was approved.
Open Access This article is distributed under the terms of the Creative Commons Attribution 4.0 International License (http:// creativecommons.org/licenses/by/4.0/), which permits unrestricted use, distribution, and reproduction in any medium, provided you give appropriate credit to the original author(s) and the source, provide a link to the Creative Commons license, and indicate if changes were made.

\section{References}

1. Rhodes A, Evans LE, Alhazzani W, Levy MM, Antonelli M, Ferrer R, Kumar A, Sevransky JE, Sprung CL, Nunnally ME, Rochwerg B, Rubenfeld GD, Angus DC, Annane D, Beale RJ, Bellinghan GJ, Bernard GR, Chiche JD, Coopersmith C, De Backer DP, French CJ, Fujishima S, Gerlach H, Hidalgo JL, Hollenberg SM, Jones AE, Karnad DR, Kleinpell RM, Koh Y, Lisboa TC, Machado FR, Marini JJ, Marshall JC, Mazuski JE, McIntyre LA, McLean AS, Mehta S, Moreno RP, Myburgh J, Navalesi P, Nishida O, Osborn TM, Perner A, Plunkett CM, Ranieri M, Schorr CA, Seckel MA, Seymour CW, Shieh L, Shukri KA, Simpson SQ, Singer M, Thompson BT, Townsend SR, Van der Poll T, Vincent JL, Wiersinga WJ, Zimmerman JL, Dellinger RP (2017) Surviving sepsis campaign: international guidelines for management of sepsis and septic shock: 2016. Intensive Care Med 43(3):304-377. https:// doi.org/10.1007/s00134-017-4683-6

2. Rello J, van Engelen TSR, Alp E, Calandra T, Cattoir V, Kern WV, Netea MG, Nseir S, Opal SM, van de Veerdonk FL, Wilcox MH, Wiersinga WJ (2018) Towards precision medicine in sepsis: a position paper from the European Society of Clinical Microbiology and Infectious Diseases. Clin Microbiol Infect. https://doi.org/10. 1016/j.cmi.2018.03.011

3. Scheer CS, Fuchs C, Grundling M, Vollmer M, Bast J, Bohnert JA, Zimmermann K, Hahnenkamp K, Rehberg S, Kuhn SO (2018) Impact of antibiotic administration on blood culture positivity at the beginning of sepsis: a prospective clinical cohort study. Clin Microbiol Infect. https://doi.org/10.1016/j.cmi.2018.05.016

4. Phua J, Ngerng W, See K, Tay C, Kiong T, Lim H, Chew M, Yip H, Tan A, Khalizah H, Capistrano R, Lee K, Mukhopadhyay A (2013) Characteristics and outcomes of culture-negative versus culturepositive severe sepsis. Crit Care 17(5):R202. https://doi.org/10. $1186 / \mathrm{cc} 12896$

5. Sinha M, Jupe J, Mack H, Coleman TP, Lawrence SM, Fraley SI (2018) Emerging technologies for molecular diagnosis of sepsis. Clin Microbiol Rev 31(2). https://doi.org/10.1128/CMR.00089-17

6. Campion M, Scully G (2018) Antibiotic use in the intensive care unit: optimization and de-escalation. J Intensive Care Med: 885066618762747. https://doi.org/10.1177/0885066618762747

7. Afshari A, Schrenzel J, Ieven M, Harbarth S (2012) Bench-tobedside review: rapid molecular diagnostics for bloodstream infection-a new frontier? Crit Care 16(3):222. https://doi.org/10. 1186/cc11202

8. van de Groep K, Bos MP, PHM S, Rubenjan A, Gazenbeek C, WJG M, van der Poll T, Juffermans NP, DSY O, MJM B, Cremer OL, consortium M (2018) Development and first evaluation of a novel multiplex real-time PCR on whole blood samples for rapid pathogen identification in critically ill patients with sepsis. Eur J Clin Microbiol Infect Dis. https://doi.org/10.1007/s10096-018-3255-1

9. Singer M, Deutschman CS, Seymour CW, Shankar-Hari M, Annane D, Bauer M, Bellomo R, Bernard GR, Chiche JD, Coopersmith CM, Hotchkiss RS, Levy MM, Marshall JC, Martin GS, Opal SM, Rubenfeld GD, van der Poll T, Vincent JL, Angus DC (2016) The third international consensus definitions for sepsis 
and septic shock (sepsis-3). JAMA 315(8):801-810. https://doi. org/10.1001/jama.2016.0287

10. Levy MM, Fink MP, Marshall JC, Abraham E, Angus D, Cook D, Cohen J, Opal SM, Vincent JL, Ramsay G, International Sepsis Definitions C (2003) 2001 SCCM/ESICM/ACCP/ATS/SIS International Sepsis Definitions Conference. Intensive Care Med 29(4):530-538. https://doi.org/10.1007/s00134-003-1662-x

11. Klein Klouwenberg PM, Ong DS, Bos LD, de Beer FM, van Hooijdonk RT, Huson MA, Straat M, van Vught LA, Wieske L, Horn J, Schultz MJ, van der Poll T, Bonten MJ, Cremer OL (2013) Interobserver agreement of Centers for Disease Control and Prevention criteria for classifying infections in critically ill patients. Crit Care Med 41(10):2373-2378. https://doi.org/10.1097/CCM. 0b013e3182923712

12. Deitch EA (2012) Gut-origin sepsis: evolution of a concept. Surgeon 10(6):350-356. https://doi.org/10.1016/j.surge.2012.03. 003

13. Doig CJ, Sutherland LR, Sandham JD, Fick GH, Verhoef M, Meddings JB (1998) Increased intestinal permeability is associated with the development of multiple organ dysfunction syndrome in critically ill ICU patients. Am J Respir Crit Care Med 158(2):444 451. https://doi.org/10.1164/ajrccm.158.2.9710092

14. Vincent JL, Brealey D, Libert N, Abidi NE, O'Dwyer M, Zacharowski K, Mikaszewska-Sokolewicz M, Schrenzel J, Simon F, Wilks M, Picard-Maureau M, Chalfin DB, Ecker DJ, Sampath R, Singer M Rapid diagnosis of infections in the critically ill T (2015) rapid diagnosis of infection in the critically ill, a multicenter study of molecular detection in bloodstream infections, pneumonia, and sterile site infections. Crit Care Med 43(11):2283-2291. https://doi. org/10.1097/CCM.0000000000001249

15. Dark P, Blackwood B, Gates S, McAuley D, Perkins GD, McMullan R, Wilson C, Graham D, Timms K, Warhurst G (2015) Accuracy of LightCycler((R)) SeptiFast for the detection and identification of pathogens in the blood of patients with suspected sepsis: a systematic review and meta-analysis. Intensive Care Med 41(1):21-33. https://doi.org/10.1007/s00134014-3553-8

16. Tassinari M, Zannoli S, Farabegoli P, Pedna MF, Pierro A, Mastroianni A, Fontan R, Luongo L, Sarnataro G, Menegatti E, Caruso A, Sambri V (2018) Rapid diagnosis of bloodstream infections in the critically ill: evaluation of the broad-range PCR/ESIMS technology. PLoS One 13(5):e0197436. https://doi.org/10. 1371/journal.pone.0197436

17. Ziegler I, Fagerstrom A, Stralin K, Molling P (2016) Evaluation of a commercial multiplex PCR assay for detection of pathogen DNA in blood from patients with suspected sepsis. PLoS One 11(12): e0167883. https://doi.org/10.1371/journal.pone.0167883

18. Stevenson M, Pandor A, Martyn-St James M, Rafia R, Uttley L, Stevens J, Sanderson J, Wong R, Perkins GD, McMullan R, Dark P (2016) Sepsis: the LightCycler SeptiFast test MGRADE(R), SepsiTest and IRIDICA BAC BSI assay for rapidly identifying bloodstream bacteria and fungi - a systematic review and economic evaluation. Health Technol Assess 20(46):1-246. https://doi.org/ $10.3310 /$ hta20460

19. De Angelis G, Posteraro B, De Carolis E, Menchinelli G, Franceschi F, Tumbarello M, De Pascale G, Spanu T, Sanguinetti M (2018) T2Bacteria magnetic resonance assay for the rapid detection of ESKAPEc pathogens directly in whole blood. J Antimicrob Chemother 73(suppl_4):iv20-iv26. https://doi.org/10.1093/jac/ dky049

Publisher's note Springer Nature remains neutral with regard to jurisdictional claims in published maps and institutional affiliations. 